\title{
Introduction of 5G as a Next-generation Mobile Network
}

\author{
Ruhul Amin \\ Senior Data Entry Control Operator (IT), ED-Maintenance Office, \\ Bangladesh Bank (Head Office), Dhaka, BANGLADESH \\ *(ruhulaminshuzon@gmail.com)
}

\begin{abstract}
This journal is licensed under a Creative Commons Attribution-Noncommercial 4.0 International License (CC-BY-NC). Articles can be read and shared for noncommercial purposes under the following conditions:

- BY: Attribution must be given to the original source (Attribution)

- NC: Works may not be used for commercial purposes (Noncommercial)

This license lets others remix, tweak, and build upon your work non-commercially, and although their new works must also acknowledge you and be non-commercial, they don't have to license their derivative works on the same terms.

License Deed Link: http://creativecommons.org/licenses/by-nc/4.0/

Legal Code Link: http://creativecommons.org/licenses/by-nc/4.0/legalcode

$A B C$ Research Alert uses the CC BY-NC to protect the author's work from misuse.
\end{abstract}

\begin{abstract}
5G aren't just about significantly improving network connectivity. It's a next-generation mobile network that promises to be a game changer in the way we live. The true breakthrough of $5 \mathrm{G}$ is the capacity of up to 1,000 5G connected devices per person. It covers all 7 billion people worldwide. One of the great expectations for the future is that not only will all humans be connected to the Internet, but most items of our lives will also be connected. With 5G, coverage will be improved, capacity will be increased, latency will be reduced, and data speed will significantly improve. Future 5G solutions will outperform current 4G mobile networks in several ways. Significant improvements in device density, transfer speeds and latencies, and a $90 \%$ reduction in power consumption are just a few of the $5 \mathrm{G}$ goals.

On the other hand, the harmful effects of frequency radiation have already been proven. Even before $5 \mathrm{G}$ was proposed, dozens of petitions and appeals by international scientists, including the Flyberger appeal signed by more than 3,000 doctors, stopped the expansion of wireless technology and made new base stations. Requested a moratorium. Negative microbiological effects have also been recorded. Government regulators will consider deploying 5G, especially with the additional infrastructure needed to expand their networks. 5G deployments need to address both standard and advanced cybersecurity threats. It is the responsibility of the carrier and network consortium to provide customers with digital safety nets, except that customer complacency can be an issue as well.
\end{abstract}

\section{Keywords}

5G, Mobile Network, Technology, Internet Services, Internet of things, Digital Safety

\section{INTRODUCTION}

$5 \mathrm{G}$ is a next-generation mobile network that promises to be a game changer in the way we live. And the challenges of $5 \mathrm{G}$ aren't just about significantly improving network connectivity. It offers new opportunities and makes it possible to provide breakthrough solutions that reach society as a whole. Imagine billions of connected devices that collect and share information in real time to reduce road accidents. Or a lifesaving application that allows you to fly thanks to a guaranteed lag-free connection. Or because you can predict the production line, you can prevent interruptions before they occur. It's a 
big claim, but over the last decade, we've seen fundamental changes in both consumer behavior and business. Advances in mobile technology are a key driver of these changes.

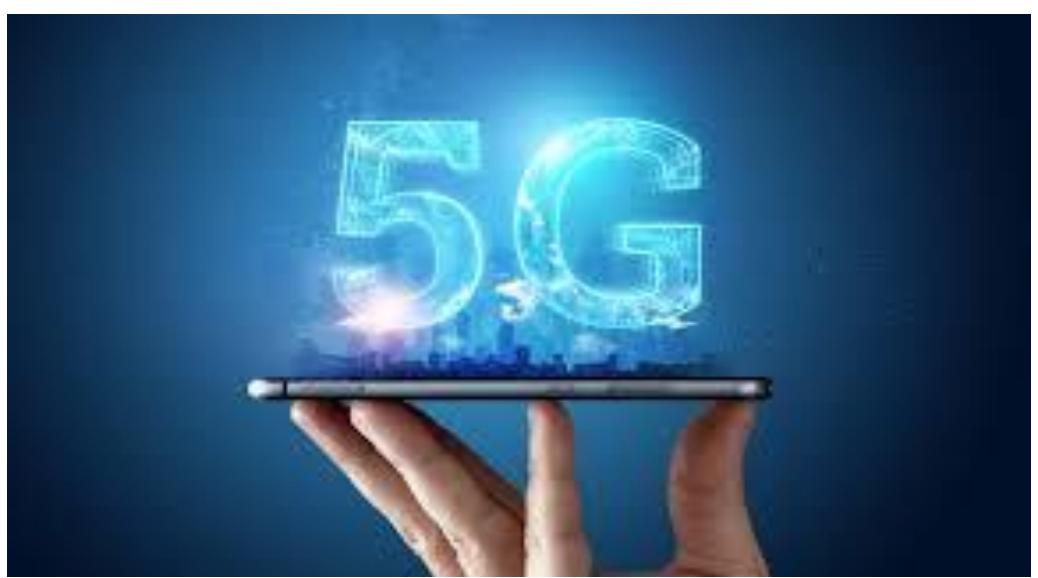

Figure 1: $5 \mathrm{G}$ is a next-generation mobile network that potentials that promises better tomorrow.

\section{MAXIMUM CAPACITY AND SPEEDS}

Patrick wasn't very interested in talking about $5 \mathrm{G}$ speeds. As he pointed out, most people are already happy with the maximum speed of $4 \mathrm{G}$. The true breakthrough of $5 \mathrm{G}$ is the capacity of up to $1,0005 \mathrm{G}$ connected devices per person. It covers all 7 billion people worldwide (some use technologies such as WiFi and Bluetooth). This will enable the future of the Internet of Things (IoT), which will come back later.

\begin{tabular}{|c|c|c|c|c|c|}
\hline Generation & $1 \mathrm{G}$ & $2 \mathrm{G}$ & $3 G$ & $4 \mathrm{G}$ & $4 \mathrm{G}$ \\
\hline Deployment & $1970 / 1984$ & $1980 / 1989$ & $1990 / 2002$ & $2000 / 2010$ & $2017 / 2020$ \\
\hline Data Bandwidth & $2 \mathrm{Kbps}$ & 14-64 Kbps & $2 \mathrm{Kbps}$ & $200 \mathrm{Kbps}$ & 1 Gbps \\
\hline & AMPS & $\begin{array}{c}\text { TDMA, CDMA, } \\
\text { GPS, GPRS }\end{array}$ & WCDMA & $\begin{array}{l}\text { Single unified } \\
\text { standard }\end{array}$ & $\begin{array}{l}\text { Single unified } \\
\text { standard }\end{array}$ \\
\hline Technology & $\begin{array}{l}\text { Analog cel- } \\
\text { lular }\end{array}$ & Digital Cellular & $\begin{array}{l}\text { Broadband with } \\
\text { CDMA, IP } \\
\text { technology }\end{array}$ & $\begin{array}{c}\text { Unified IP and } \\
\text { seamless combination } \\
\text { of broadband LAN, } \\
\text { WAN and WLAN }\end{array}$ & $\begin{array}{c}\text { Unified IP and } \\
\text { seamless combina- } \\
\text { tion of broadband } \\
\text { LAN, WAN and } \\
\text { WLAN and WWWW }\end{array}$ \\
\hline Services & $\begin{array}{c}\text { Mobile } \\
\text { Technol- } \\
\text { ogy (voice) }\end{array}$ & $\begin{array}{c}\text { Digital voice, } \\
\text { SMS, Higher ca- } \\
\text { pacity packetized }\end{array}$ & $\begin{array}{l}\text { Integrated high } \\
\text { quality audio } \\
\text { and video }\end{array}$ & $\begin{array}{c}\text { Dynamic Information } \\
\text { Access, Wearable } \\
\text { devices }\end{array}$ & $\begin{array}{c}\text { Dynamic } \\
\text { Information Access, } \\
\text { Wearable devices } \\
\text { with AI capabilities }\end{array}$ \\
\hline Multiplexing & FDMA & CDMA, TDMA & CDMA & CDMA & CDMA \\
\hline Switching & Circuit & Circuit and panel & Packet & All Packet & All Packet \\
\hline Core Network & Horizontal & Horizontal & Horizontal & $\begin{array}{c}\text { Horizontal and } \\
\text { Vertical }\end{array}$ & $\begin{array}{c}\text { Horizontal and } \\
\text { Vertical }\end{array}$ \\
\hline
\end{tabular}

Table 1: The difference between all the 5 generations LTE's are shown in the below tabular representation

Another important point is that $5 \mathrm{G}$ aims to reduce perceptual delay of 1 millisecond and power consumption from wireless units by up to $90 \%$. This makes it much easier to design $5 \mathrm{G}$ connected devices that will be part of our daily lives. $5 \mathrm{G}$ is also designed to reach a maximum data rate of $10 \mathrm{~Gb}$ / s. This is 100 times faster than the maximum $100 \mathrm{Mb} / \mathrm{s}$ that $4 \mathrm{G}$ is currently reaching. This will enable new industries, media and entertainment services.

\section{THE IOT (AND THE PLANET) DEPENDS ON 5G}

One of the great expectations for the future is that not only will all humans be connected to the Internet, but most items of our lives will also be connected. This is called the Internet of Things (IoT). By connecting all smart devices to the Internet, you can realize smart homes, increase energy efficiency, save time on housekeeping and shopping, and use safer and more efficient public and private transportation. 
While today's mobile network technology isn't quite ready to fully handle these devices, this process is an evolution and the first IoT solutions are being rolled-out on today's mobile networks.

The IOT relies entirely on network devices that use mobile networks that are energy efficient, reliable, and support much higher device densities. 5G plays an important role here. If society wants to enjoy all the benefits of the IoT, such as reducing carbon dioxide emissions, living longer, and improving production and transportation efficiency, we need to welcome a new generation of mobile networks with open arms.

\section{G MAY COME HERE SOONER THAN YOU THINK}

Patrick says 5G is just around the corner. Major technological advances tend to be announced in connection with the world's largest sporting events, such as the Olympic Games. Patrick states that the first commercial 5G network will be available to most people by the 2020 Japan Olympics.

Among the biggest drivers of 5G development are manufacturers of 5G-enabled devices such as automakers, internet technology companies, media, medical industry and telecommunications companies. Because 5G's infrastructure and capabilities rely more on software than $4 \mathrm{G}$ and its predecessors, there is much more interest from companies outside the traditional telecommunications industry developing the next mobile network.

It is exciting and historically unmatched that companies planning to deliver content and services via $5 \mathrm{G}$ networks are deeply involved in defining new network infrastructure specifications and features. There is no such thing. This pushes technology faster, delivering better service and more specialized services and features in the final product. Affect $5 \mathrm{G}$ on automotive industry and mobility

New mobile technologies are fundamentally disrupting the automotive industry. We have all seen smart cars. In Norway, "self-driving" Tesla models are routinely seen, surpassing car sales in the last three years. Many other car makers also claim that the latest models are smarter than ever, with computer-assisted driving and technically advanced security features.

\section{SMART, BUT NOT SMART ENOUGH}

All smart cars on the market today have one major weakness in common. It relies solely on its own sensors and cameras for operation and navigation. However, the new 5G mobile network is designed with the automotive industry in mind.

With 5G, coverage is improved, capacity is increased, latency is reduced, and data speed is significantly improved. This not only allows cars to stream Spotify on long journeys, but also allows them to drive themselves by collecting information from other cars, pedestrians, traffic lights, and even the road itself along the way.

To visualize this, Patrick tells us to imagine our car talking to everyone who meets everything. Controlled by computers (or thousands of computers) in the cloud, it calculates and adjusts the vehicle every millisecond.

Our vehicle's self-contained "intelligence" from the onboard computer exists only as an emergency backup in the event of a loss of internet connection or to serve as a support for vehicle handling. Even without the Internet, the 5G capabilities of car-to-car, car-to-road, and car-to-pedestrian communications play an important role in safe travel from A to B.

\section{SPECIAL REQUIREMENTS FROM 5G NETWORKS}

Most of the 5G networks are designed by the automotive industry. Organizations such as the 5G Automotive Association (5GAA) are telecom and technology companies.

The most important factors for $5 \mathrm{G}$ to reach its full potential are:

- High mobile connectivity, fast connectivity to devices, and fast, stable connectivity

- Short wait times for important road information and potentially dangerous highway situations 
- High device density features as many devices are connected (or passed) to a small area at the same time

- Security, vehicle hacking, and interception of sensitive data are becoming more and more issues, and communication between devices should be as secure as possible.

- Extreme reliability is important, especially for autonomous steering and navigation.

Perhaps the biggest challenge for $5 \mathrm{G}$ networks and connected cars is land coverage and associated costs. With vast areas of roads with little or no signal from today's mobile networks, $5 \mathrm{G}$ networks are created at base stations at far shorter distances than today's 4G (and earlier) equipment. May be done. Obviously, in these situations, the car needs to be able to safely fall back to the onboard computer and in some cases can be driven manually (Donepudi, 2016).

The transition from Level 4 automation (high degree of automation) to Level 5 automation (fully automated) requires significant infrastructure investment. This is well understood by those involved in smart city development. In this context, 5G can also be described as an important link between self-driving cars, smart cities, and the changing faces of urban development.

\section{INNOVATION IS IMPORTANT IN THE AUTOMOTIVE INDUSTRY}

Patrick Waldemar asserts that tomorrow's technology will bring amazing new features in terms of connectivity, capacity, and speed, but that won't happen in a vacuum.

The automotive industry recognizes the importance of innovation in every aspect of its business, including production, driving experience and safety. Therefore, all major brands are aiming to develop smarter and more connected vehicles.

To achieve this, it would be much more expensive and counterproductive for all car brands to develop their own next-generation wireless communication systems. By supporting the development of 5G and defining the specifications required for smart cars, smart cars will accelerate the progress of $5 \mathrm{G}$ and leave the test lab to enter the real world.

Over the next few years, Patrick says, there will be a gradual transition to smarter, more connected cars. This is evidenced by the fact that true $5 \mathrm{G}$ connected vehicles are already being tested today.

\begin{tabular}{|l|c|c|}
\hline Performances/Generation & 4G & 5G \\
\hline Peak data rate (Gbit/s) & 1 & 20 \\
\hline User experience data rate $(\mathrm{Mbit} / \mathrm{s})$ & 10 & 100 \\
\hline Spectrum efficiency & $1 \mathrm{x}$ & $3 \mathrm{x}$ \\
\hline Speed $(\mathrm{km} / \mathrm{h})$ & 350 & 500 \\
\hline Latency $(\mathrm{ms})$ & 10 & 1 \\
\hline Connection density $\left(\right.$ number of objects $\left./ \mathrm{km}^{2}\right)$ & 100000 & 1000000 \\
\hline Network energy efficiency & $1 \mathrm{x}$ & $100 \mathrm{x}$ \\
\hline Area traffic capacity $\left(\mathrm{Mbit} / \mathrm{s} / \mathrm{m}^{2}\right)$ & 0.1 & 10 \\
\hline
\end{tabular}

Table 2: The following table summarizes the $5 \mathrm{G}$ target performance and the performance currently available in $4 \mathrm{G}$.

\section{IMPACT OF 5G}

\section{Effects of $5 G$ on supply chain \& logistics}

Supply chains and logistics include many moving parts. Tracking all individual items and safely moving from A to B is an art form that is often unappreciated. The Internet of Things... and cargo!

You already have heard the term " IOT " (Internet of Things). The IoT means not only connecting people, but the Internet connecting almost everything we own. To realize the future with thousands of interconnected objects, such as at home, at work, and on the go, we need new mobile technologies that can handle all of this connection and data (Donepudi, 2018).

Narrowband IoT (NB-IoT), already available in several markets, is the first step in this direction, and 5 G IoT solutions will bring further improvements. Narrowband IoT (NB-IoT) is a new technology that 
uses existing 4G networks. It is energy efficient and offers high security and long distances. Future 5G solutions will outperform current $4 \mathrm{G}$ mobile networks in several ways. Significant improvements in device density, transfer speeds and latencies, and a $90 \%$ reduction in power consumption are just a few of the $5 \mathrm{G}$ goals. In just a few years, 5G-connected sensors are so cheap and highly available that you can connect everything without worrying about losing the sensor, Patrick said. The low power consumption of IoT devices also enables long life without the need for replacement.

When everything is automatically labeled, tracked and recorded, the era of lost cargo, misplaced containers, manual inefficiencies and labor losses is over. In addition, creating a transparent and optimized supply chain is made possible by always-on technology that saves time and money. Full accountability with better tracking

Cargo usually changes hands during transportation and temporary or permanent storage, thus posing a drag of responsibility, ownership and insurance within the supply chain. If the transported object was damaged between point $\mathrm{A}$ and point $\mathrm{B}$, where did the damage actually happen and who is basically to blame?

By installing a 5G connection sensor on every item inside or outside the package, supply chain stakeholders can see the location, temperature, humidity, G-force, etc. of the item at any time.

Automatically recording and sharing data with all involved (no manual checkpoints required) can reassure both businesses and customers. It also helps speed up production, streamline complex logistics processes, and reduce costs. Also, in the event of an incident, you can develop an emergency response plan sooner and give better time for mitigation.

\section{Research of Telenor: (The pioneers of 5G)}

At Telenor Research, Patrick Waldemar sent hundreds of sensors for college and entrepreneurship to experiment with. The goal is to come up with new and innovative ways to harness the power of the IoT. For more information, see Telenor Start IoT. According to Patrick, we need a pioneer to push today's technology to the limit so we can see what challenges tomorrow's solutions need to overcome.

At Wallenius Wilhelmsen, we look for ways to get the most out of technologies such as IoT and 5G to maximize reliability, streamline operations, and deliver greater intelligence, efficiency, and sustainability to our customers' outbound supply chains. doing.

A huge amount of data is not enough. You need to use smart software on an unprecedented scale. This is the encounter between IoT and big data. This is the future and we are excited to be part of it.

\section{EVALUATION TO 5G, IOT \& INDUSTRY 4.0}

\section{Ground-based $5 G$}

To transmit the vast amounts of data needed for the Internet of Things (IoT), 5G technology uses millimeter waves, which, when fully deployed, are difficult to transmit over solid materials. This requires all carriers to install base stations every 100 meters in all cities around the world (Donepudi, 2018a).

Unlike previous generation wireless technologies, where a single antenna broadcasts extensively, 5G base stations and 5G devices have multiple antennas located in a "phased array" (Donepudi, 2017a). Laser-like beams that track each other. Each 5G phone contains dozens of small antennas, all of which work together to track and aim a beam focused on the nearest cell tower. The Federal Communications Commission (FCC) has adopted a rule that allows the effective power of these beams to be 20 watts, which is 10 times the level allowed on current telephones.

Each $5 \mathrm{G}$ base station contains hundreds or thousands of antennas that simultaneously direct multiple laser-like beams to all mobile phones and user devices in the service area. This technology is called "multi-input, multi-output" or MIMO. FCC regulations allow the effective radiated power of 5G base station beams to be 30,000 watts per $100 \mathrm{MHz}$ spectrum, or an equivalent spectrum of 300,000 watts / 
$\mathrm{GHz}$, from tens of times above the permissible level. It is hundreds of times more powerful. Current base station.

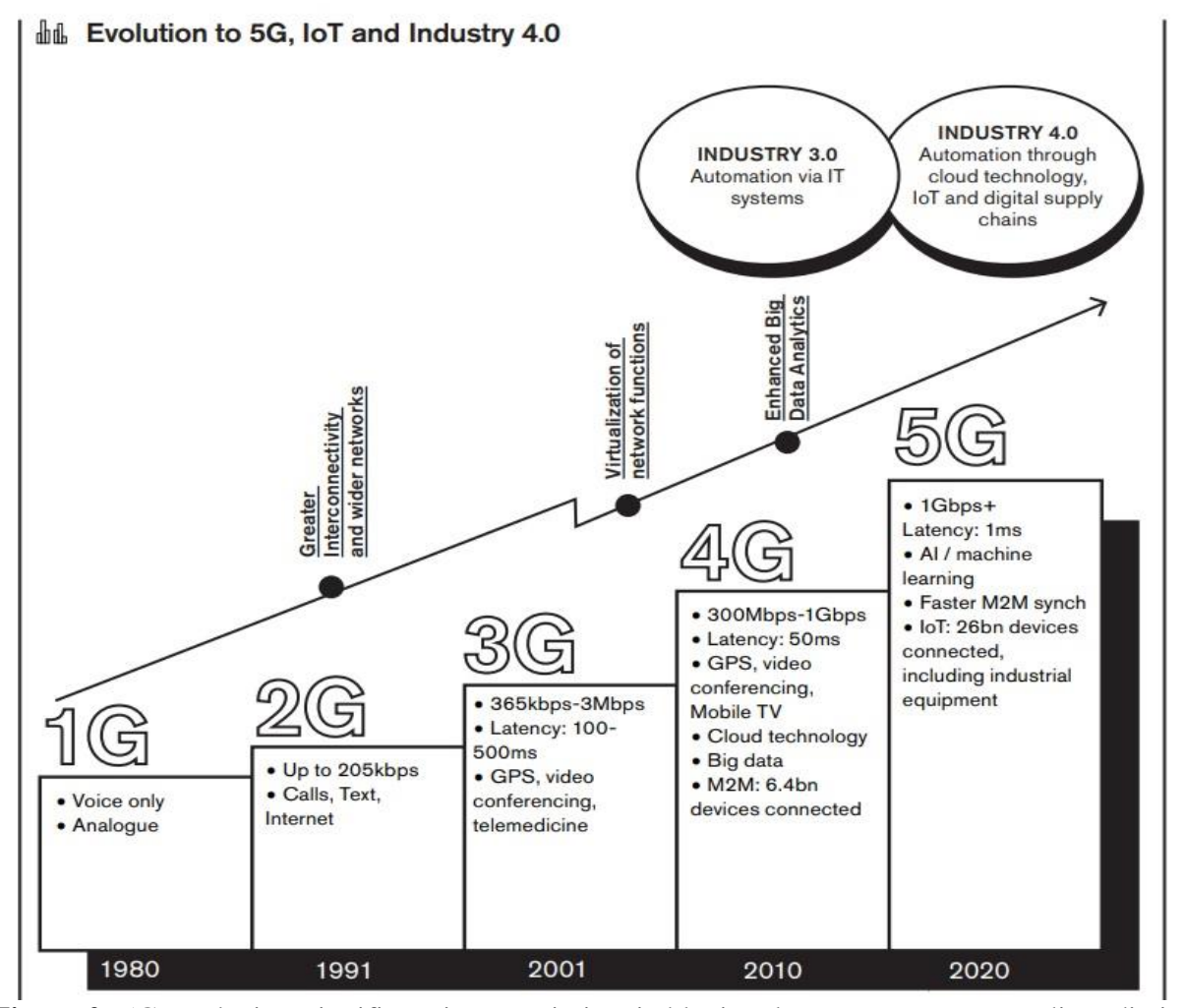

Figure 2: $5 \mathrm{G}$ results in a significant increase in inevitable, involuntary exposure to radio radiation

\section{Space-based $5 G$}

At least five companies have proposed providing $5 \mathrm{G}$ from space from a total of 20,000 low-earth and medium-earth orbit satellites that cover the Earth with powerful, focused and maneuverable beams. Each satellite emits millimeter waves with effective radiated power of up to 5 million watts (Donepudi, 2017). from thousands of antennas located in a phased array. The energy that reaches the ground from satellites is less than the energy from ground antennas, but it illuminates areas of the earth that other transmitters do not reach, adding to ground-based 5G transmissions from billions of IoT objects. I will. More importantly, satellites are located in the Earth's magnetosphere and have a significant impact on the electrical properties of the atmosphere. Changes in the Earth's electromagnetic environment can be even more life-threatening than radiation from ground antennas.

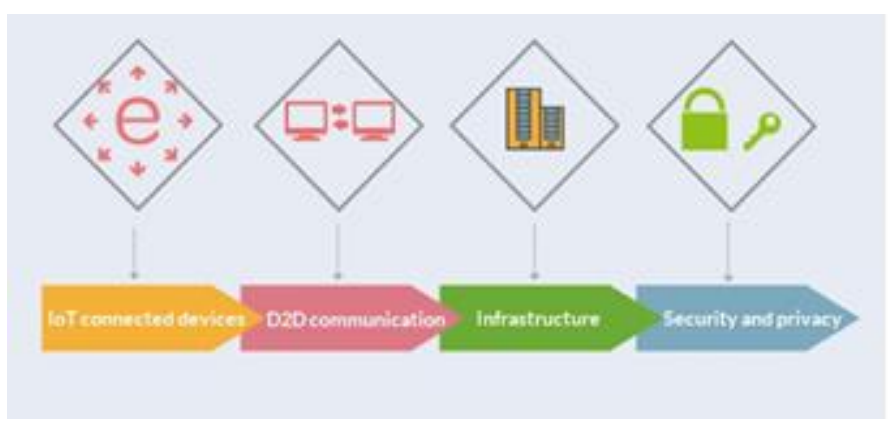

Figure 3: 5G Challenges

\section{THE HARMFUL EFFECTS OF FREQUENCY RADIATION}

The harmful effects of frequency radiation have already been proven. Even before 5G was proposed, dozens of petitions and appeals by international scientists, including the Flyberger appeal signed by 
more than 3,000 doctors, stopped the expansion of wireless technology and made new base stations. Requested a moratorium. In 2015, 215 scientists from 41 countries warned the United Nations (UN) and the World Health Organization (WHO). They said, "Many recent scientific publications show that EMF [electromagnetic fields] affect living organisms at levels well below most international and national guidelines." It was. Over 10,000 peer-reviewed scientific studies have shown the harm to human health from RF radiation. Effects include:

- Changes in heart rhythm

- Changes in gene expression

- Metabolic changes

- Changes in stem cell development

- Cancer

- Cardiovascular disease

- Cognitive dysfunction

- DNA damage

- Impact on general well-being

- Increased free radicals

- Learning and memory loss

- Deterioration of sperm function and quality

- Abortion

- Neurological injury

- Obesity and diabetes

- Oxidative stress

Effects in children include autism, attention deficit hyperactivity disorder (ADHD), and asthma. Damage goes well beyond the humanity, as there's abundant evidence of harm to diverse plant and wildlife and laboratory animals, including:

- Birds

- Forests

- Frogs

- Fruit flies

- Honey bees

- Insects

- Mammals

- Mice

- Plants

- Rats

- Trees

Negative microbiological effects have also been recorded. In 2011, the WHO International Agency for Research on Cancer (IARC) concluded that RF radiation with frequencies between $30 \mathrm{kHz}$ and 300 $\mathrm{GHz}$ could be carcinogenic to humans (Group 2B). However, recent evidence, including the latest studies on cell phone use and the risk of brain tumors, has shown that RF radiation is carcinogenic to humans cigarette smoke and asbestos. It also indicates that it should be classified as "Group 1 Carcinogen".

Most modern wireless signals are pulse modulated. Harm is caused by both high frequency carriers and low frequency pulsations. Deployment of 5G satellites must be banned. The Earth, the ionosphere, and the lower atmosphere form the global electrical circuits in which we live. The biological rhythms of humans, birds, hamsters and spiders are controlled by the Earth's natural electromagnetic environment, and it is well established that the well-being of all living things depends on the steadiness of this environment, including the electrical properties of the atmosphere... In a groundbreaking paper, Cherry explained the importance of Schumann resonance and why ionosphere disorders alter blood pressure and melatonin, causing "cancer, reproduction, heart and nerve disease and death." 


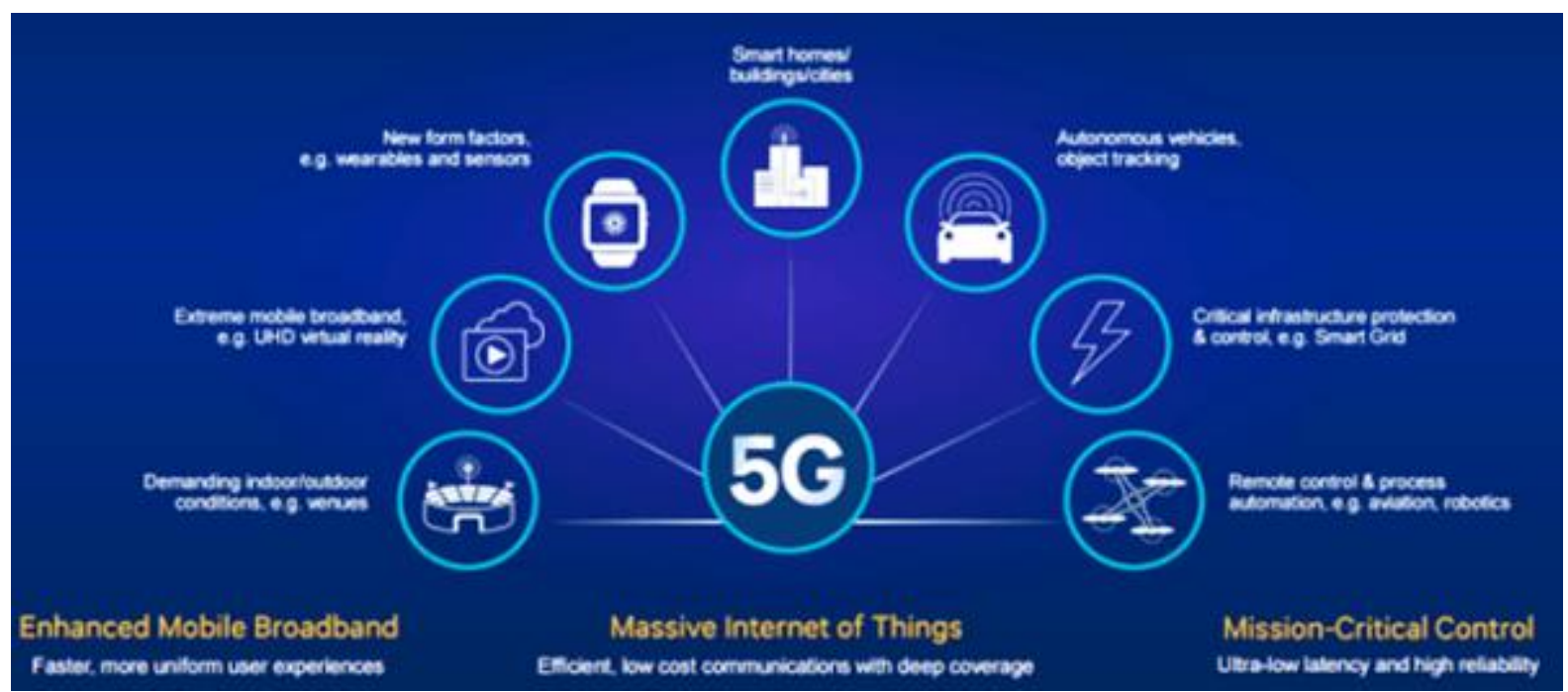

Figure 4: 5G will enhance existing and expand to new use cases

These elements of our electromagnetic environment have already been altered by radiation from power lines. Harmonic radiation of power lines reaches the Earth's ionosphere and magnetosphere, where it's amplified by wave particle interactions. In 1985, Dr. Robert O. Becker said that the harmonic radiation of power lines has already altered the structure of the magnetosphere, and the continued expansion of this effect "threats the viability of all life on Earth." I warned you. Placing tens of thousands of satellites directly in both the ionosphere and the magnetosphere and emitting modulated signals at millions of watts and millions of frequencies can change the electromagnetic environment beyond adaptive capacity.

Informal surveillance has already provided evidence of serious human and animal impacts from approximately 100 satellites providing $2 \mathrm{G}$ and $3 \mathrm{G}$ telephone services from low earth orbit since 1998 . Such effects cannot be understood simply by considering the low levels of radiation on the ground. Knowledge from other relevant scientific disciplines, including those in atmospheric physics and acupuncture, should be taken into account. The addition of 20,000 5G satellites could further pollute the world's electrical circuits and change the Schumann resonance, which has evolved all life on Earth. The impact is universal and can cause serious damage.

\section{FREQUENCY BAND}

4G LTE already operates in the established frequency band below $6 \mathrm{GHz}$, but $5 \mathrm{G}$ requires frequencies up to 300GHz. Some are well known as millimeter waves. These bands carry much more capacity and can achieve ultra-fast speeds that are 20 times faster than LTE's fastest theoretical throughput.

Wireless operators need to bid on higher spectral bands as they build and deploy their respective 5G networks. In Canada, for example, the federal government will hold a $600 \mathrm{MHz}$ spectrum auction in 2019 , with $3500 \mathrm{MHz}$ continuing in 2020 and $1 \mathrm{GHz}$ currently planned for 2021 . It may increase further after that. In the United States, the millimeter-wave (mmWave) spectrum auction won $\$ 4.47$ billion (US) as of the spring of 2020. This is the largest single sum in the history of the country.

\section{DEPLOYMENT AND COVERAGE}

5G offers significant speed and bandwidth gains, but its limited range requires more infrastructure. Higher frequencies allow for highly directional radio waves. In other words, you can target and aim. This is a technique called beamforming. The challenge is that $5 \mathrm{G}$ antennas can process data with more users, while emitting beams at shorter distances.

Even if the antennas and base stations are smaller in this scenario, many of them will need to be installed in buildings and homes. Cities will probably need to install additional repeaters to spread the waves 
over a wide area while maintaining a constant velocity in densely populated areas. Until the 5G network matures, carriers may continue to use the low frequency band to cover a larger area.

In the future, modems and Wi-Fi routers will be replaced by $5 \mathrm{G}$ small cells and other hardware, bringing 5G connectivity to homes and businesses, which could eliminate current wired Internet connectivity. Expanding access to rural areas is as big a challenge as it is for LTE.

\section{CONSTRUCTION COST, PURCHASE COST}

Building a network is expensive, and carriers raise money to do so by increasing customer revenue. Just as LTE plans have higher upfront costs, $5 \mathrm{G}$ will follow a similar path. It not only builds layers on top of existing networks, but also lays the foundation for something entirely new.

Global spending on $5 \mathrm{G}$ is expected to reach $\$ 88$ billion by 2023 , according to heavy-reading mobile operator 5G Capex. When it becomes truly viable, certain device segments, especially vehicles, appliances, robots, and urban infrastructure, will be connected in a whole new way.

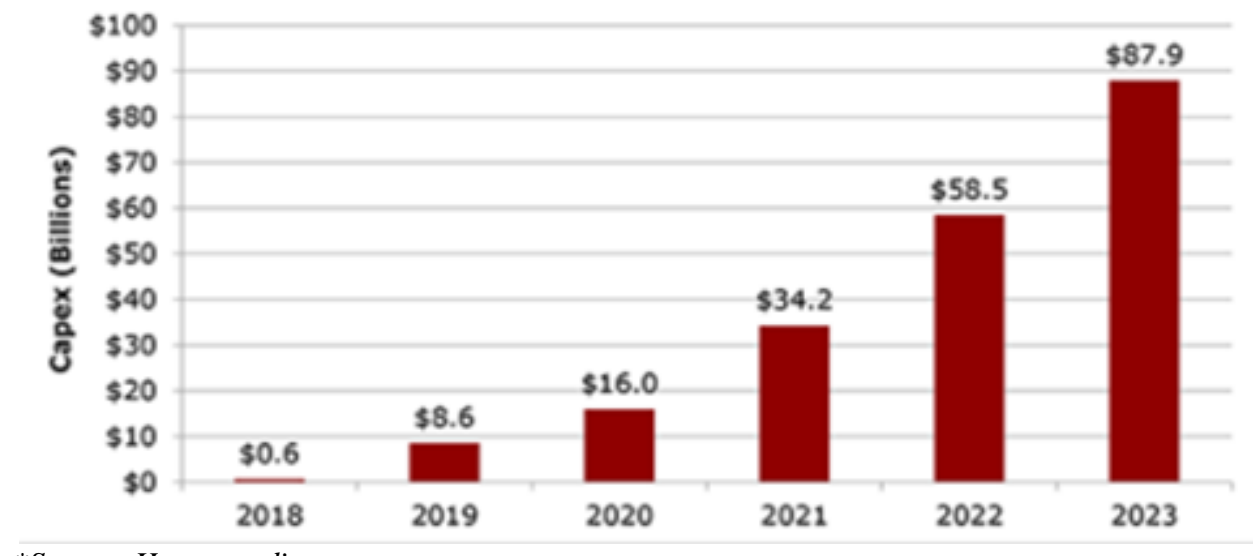

* Source: Heavy reading

Figure 5: Forecast Annual Global 5g Capex by Mobile Operators

With 5G-enabled smartphones and other devices pervading the market, networks are evolving in different countries around the world. Self-driving car technology is already on the market in limited form, but fully self-driving cars are a few years away and will be blind drive if ultra-fast networks like $5 \mathrm{G}$ do not communicate.

The concepts behind the Internet of Things (IoT) are based on high-speed networks that can connect devices and services. This is one of the promises analysts have predicted about the potential of 5G, but people will first want to see how the additional speeds will enrich their lives.

\section{REGULATIONS AND STANDARDS}

Government regulators will consider deploying 5G, especially with the additional infrastructure needed to expand their networks. Providers will need to install new antennas, base stations, and repeaters.

Beyond that, regulators need to work on $5 \mathrm{G}$ services in a wave across multiple vertical sectors. These include spectrum availability, EMF radiation regulation, infrastructure sharing, and cybersecurity. The Research and Markets report details the different aspects and challenges of getting there.

Canada's largest telecommunications carriers have decided to build their networks within the regulatory limits set by the Canadian Innovation, Science and Economic Development (ISED), Canadian Radio-television and Communications Commission (CRTC), and Health Canada. I promise.

In the United States, all four major carriers run $5 \mathrm{G}$ networks with limited connectivity to selected markets. The Federal Communications Commission (FCC) has chosen not to change RF frequency limits 
or regulations related to $5 \mathrm{G}$ deployments. It may also open the door for small players and new entrants to provide local and regional services.

In Europe, UK carriers are already working on their respective plans to expand in 2020, despite backlashes and attacks on carriers and towers. National communications regulators consider 5G signals to be within internationally recognized guidelines.

The European Union has actively promoted 5G development as part of its economic growth program and has provided details on how Member States will engage in research and standards. The spectrum auction postponed due to the pandemic may take place by the end of 2020 .

Meanwhile, China already has 50 million 5G phone subscribers, which is expected to reach $70 \%$ of $5 \mathrm{G}$ smartphone contracts by the end of 2020. South Korea is lagging behind, but Thailand intends to expand its own network and Thailand is at a leading pace. Road to Southeast Asian countries.

\section{SECURITY AND PRIVACY}

While this is a challenge for data-driven technologies, $5 \mathrm{G}$ deployments need to address both standard and advanced cybersecurity threats. 5G falls under the Authentication and Key Agreement (AKA), a system designed to establish trust between networks, but it is now possible to track nearby people using the telephone. They could even eavesdrop on live phones.

\section{CONCLUSIONS}

As it is today, it is the responsibility of the carrier and network consortium to provide customers with digital safety nets, except that customer complacency can be an issue as well. Data speeds are expected to be much faster than current levels, which also improves connectivity. This allows cloud-based data virtualization services to be as airtight as possible to protect user data and privacy. Similarly, users need to be more vigilant as data administrators.

\section{REFERENCES}

Donepudi, P. (2016). Influence of Cloud Computing in Business: Are They Robust? Asian Journal of Applied Science and Engineering, 5(3), 193-196. https://doi.org/10.5281/zenodo.4110309

Donepudi, P. (2017a). AI and Machine Learning in Banking: A Systematic Literature Review. Asian Journal of Applied Science and Engineering, 6(3), 157-162. https://doi.org/10.5281/zenodo.4109672

Donepudi, P. K. (2017b). Machine Learning and Artificial Intelligence in Banking. Engineering International, 5(2), 83-86. https://doi.org/10.18034/ei.v5i2.490

Donepudi, P. K. (2018a). AI and Machine Learning in Retail Pharmacy: Systematic Review of Related Literature. ABC Journal of Advanced Research, 7(2), 109-112. https://doi.org/10.18034/abcjar.v7i2.514

Donepudi, P. K. (2018b). Application of Artificial Intelligence in Automation Industry. Asian Journal of Applied Science and Engineering, 7(1), 7-20. http://doi.org/10.5281/zenodo.4146232 